\title{
The Palace of Discovery at the Paris International Exhibition, I937
}

\author{
By Dr. Pierre Biquard
}

$\mathrm{E}$ VERY day thousands of visitors from all parts of the world enter the Palace of Discovery of the Paris International Exhibition. Some go as experts to see how far science lends itself to spectacular demonstration. Others, realizing their lack of knowledge, go to learn. Furthermore, some people, especially the young, go brimful of eager curiosity, hoping to find somewhere in those halls an inspiration which will guide them in the choice of their career.

One thing is certain, no one is disappointed. It is obviously impossible to cover in a brief article the entire field of present-day science, and relate the history of scientific progress up to date. This is merely a brief statement of what has been achieved in the different sections of the Palace of Discovery. The Palace covers an area of 23,000 square metres. All branches of scientific learning are represented, from mathematics and astronomy to medicine and botany.

The greatest efforts have been made to replace by real demonstrations the silent testimony of documents and pictures. In all sections a staff of demonstrators escort the visitors and carry out experiments, though many work automatically and can be set in motion by the public. The magnitude of the undertaking is shown by the single fact that the electrical installation of the Great Palace is on a greater scale than that of a whole district in Paris : ten kilometres of feeders and sixty kilometres of cables were needed, and it is estimated that the cost of the electricity used during the course of the Exhibition will amount to 1,000,000 francs.

In accordance with the views of Auguste Comte, mathematies will be dealt with first. It may be true, as Emile Borel wrote in Paris, 1937, that "only those who have given up their lives to mathematical research know what it is, what are its aims and by what means it attains them" ; nevertheless the rooms set apart for mathematics show to all visitors the development of this science from the earliest times and the growing importance that it has acquired in modern developments of physies, chemistry, biology, etc. Certain questions are explained by means of films : in this way visitors are introduced to such subjects as four dimensional space and the laws of similitude, showing that if the dimensions of an individual were increased ten times he would collapse under his own weight. Mathematicians are given the opportunity of working out on the spot at the blackboard problems the solutions to which are posted up the following day. It is interesting to see that the eternal riddle of the squaring of the circle occupies a place, and the value of $\pi$ to 707 places of decimals is exhibited on the surface of a cupola.

The task undertaken by those responsible for the astronomy section has been no small one. They have had to crowd into a few rooms all that is known about a universe so vast that light takes a thousand million years to traverse it. Three models show the structure of portions of space of decreasing sizes : the first represents the galaxy, the diameter of which is of the order of five million light years : the second shows the sun and the twenty-five stars surrounding it in a portion of space through which light travels in twenty-five years: finally, the third model shows the sun and its attendant planets, that is, a very small space through which light travels in seventeen hours. The northern Milky Way is shown in a photographic enlargement measuring $20 \mathrm{~m}$. $\times 4 \cdot 5 \mathrm{~m}$.; there are also many good photographs of nebulæ, of the sun, moon, planets, comets, etc. The movements of the planets in the solar system are reproduced in the great planetarium, and to make them more clearly visible, the rates of their revolutions have been multiplied by 432,000 , allowing one revolution of Mercury around the sun to be seen in eighteen seconds. After having examined all that can be seen in space from the earth, the visitor naturally wonders what our world would look like to other beings living on some other planet. An answer to this question is given by a model $70 \mathrm{~cm}$. in diameter which was made as the result of the observations of explorers of the stratosphere.

Physics occupies a favoured position in the Palace of Discovery. In a room dedicated to Galileo are seen the fundamental experiments relating to falling bodies, the oscillations of the pendulum, centrifugal force, the laws of composition of forces. All the foundations of the so-called 'rational' mechanics are there, and it is impossible not to dwell on the scientific progress in physics and astronomy made on this basis up to the time when its application to optics was found to be impossible.

The history of our knowledge concerning light appears in the section devoted to optics. After having thus learnt anew the laws of reflection and refraction, and measured the velocity of the propagation of light, the visitor can watch a series of experiments on interference, diffraction, polarization, interference photography, and will then perhaps be convinced of the truth of the wave theory of light. The photo-electric phenomena which can be ex. amined later will give him food for thought.

Another section is given over to electrostatics. Once again the public may see the production of electric charges by the friction of cat skin and, on the other hand, watch the working of the Van de Graaf electrostatic machine set up under the direction of M. Joliot by MM. Lazard and Savel. This machine can produce sparks of several million volts passing between two spheres of three metres diameter.

The field of oscillations is the subject of another section in which electromagnetic and sound vibra. tions are studied. Special attention must be directed to the manner in which are exhibited the conse. quences of the discovery by Pierre and Jacques Curie of the piezo-electric property of quartz; the stabilize. tion of high-frequency emissions, quartz pianos, emission and reception of ultra-sound waves, submarine sounding, etc.

Ampère's experiments and the laws of electrodynamics lead up to the triumphs of electrotechnics. By a parallel procedure, it is possible to follow the progress which, starting with the phenomenon of thermionic emission, has led to the creation of modern radiotechnics.

Some of the most beautiful experiments are shown in a section devoted to the states of matter and the 
structure of the atom. Matter is heated, cooled, compressed under several thousand atmospheres, expanded, etc. The experiments shown on fluorescence and phosphorescence are as conclusive as they are beautiful. Last comes what is perhaps the most glorious chapter of modern science, the study of atomic particles and radiations. In this section are reproduced all the experiments which have marked a decisive step forward in the study of electrons, of $\mathrm{X}$-rays and the radiation of radioactive bodies, thus passing from the first Crookes tube to the artificial radio-elements and to the cosmic rays made visible thanks to the Wilson expansion chamber.

Four laboratories have been chosen by the chemists to show the history of their particular branch of science : an alchemist's laboratory, Lavoisier's laboratory, Berthelot's laboratory and finally a modern chemical laboratory. While further on, the 'elements' air, water and fire have a special room reserved for them. A great illuminated chart shows the periodic classification of the elements and an ingenious arrangement demonstrates the structure of all the atoms, from hydrogen to uranium. The principal analyses and syntheses are reproduced before the visitors' eyes, notably the separation of the gases of the air and the synthesis of acetylene in Berthelot's 'electric egg'. With regard to each of the important branches of this science-physical chemistry, inorganic chemistry, organic chemistry, metallurgical chemistry, photochemistry, geochemistry-it is possible to estimate how much the researches of pure science have contributed to the progress of industry (paper making, manufacture of sulphuric acid, preparation of colouring matters, dyeing and printing of materials, etc.).

Biology, as might be expected, shows here a living summary of the work of Pasteur together with an exhibit of the developments of microbiology-discoveries relating to smallpox, intestinal affections, cholera and typhus.

Medicine is divided into: (1) the diseases of nutrition, (2) cardio-vascular pathology, (3) medical physics, and (4) the history of medicine, in which special stress is laid on the fundamental part played by the discovery of auscultation. Also, for surgery, the considerable progress made in the last ten or twenty years is shown, more especially the influence of discoveries bearing on asepsis and anæsthesia. If anyone wishes to learn more about his own organism, and to know what his qualities are, both good and bad, he may take his place on the seat where the human machine is tested. There, after a series of tests, his biometric ticket will be made out and may prove useful in choosing a profession. If the results are good, he will be all the more surprised when confronted with the sensorial illusions shown in the section of psycho-physiology. Experimental biology demonstrates how living beings react to physical and chemical reagents. Plant physiology and biology are illustrated by dioramas, films and collec. tions. Finally, mention must be made of the section reserved for plant genetics, in which are exhibited the great facts of natural selection, of the formation of new species and of natural or induced changes.

Space will not permit the inclusion of the names of the many scientific men from France and abroad who have collaborated in the preparation of this great Exhibition. One exception must, however, be made in the case of the president, M. Jean Perrin. This Palace is the fruit of his untiring labours, and it is thanks to him also that France will soon possess a permanent Palace of Discovery.

It is only natural that in an exhibition representing the arts and technical sciences in modern life, scientific discovery should have its rightful place as the foundation of all progress. The Palace of Discovery brings this home to the general public and also shows the real beauty of science. Possibly, on leaving, the visitor will realize the truth of these words taken from Henri Poincaré's "Dernières Pensées": "Celui qui aura goûté à la Science, qui aura vu, ne fût-ce que de loin la splendide harmonie des lois naturelles, sera mieux disposé qu'un autre à faire peu de cas de ses petits intérêts égoïstes; il aura un idéal qu'il aimera mieux que lui-même et c'est là le seul terrain sur lequel on puisse bâtir une morale".

\section{A Mesolithic Site in Brittany*}

$\mathrm{T}$ HE Mesolithic site of Téviec, a rocky islet situated about eighteen hundred metres west of the shores of the peninsula of Quiberon in Brittany, which has been explored by M. and Mme. Péquart, is up to the present the most important station of this period that has been submitted to systematic and complete examination. Incidentally, it may be said, it gains in significance by the fact that examination of human skeletal remains from Téviec has elicited from MM. Boule and Vallois a detailed analysis of the physical characters of Mesolithic man, so far as known from the remains which have sur. vived, and a comparison of this race or type with those of the Upper Palæolithic.

The investigations leading to the discovery of the site were undertaken by $M$. and Mme. Péquart in the hope of throwing light on the domestic and tribal economy of the early inhabitants of Brittany,

* Téviec: station-nécropole mésolithique du Morbihan. Par Marth et Saint-Just Péquart, M. Boule et $\mathbf{H}$. Vallois. (Archives de l'Institut et Saint-Just Péquart, M. Boule et $H$. Vallois. (Archives de l'Institut
de paléontologie humaine, Mémoire 18.) Pp. ii $+227+19$ plates. (Paris: Masson et Cie., 1937.) 220 francs. which had been neglected by archæologists owing to their preoccupation with the all-absorbing study of the monuments of the country. For this purpose they were convinced that there was little hope of obtaining undisturbed evidence on the mainland, and consequently directed their investigations to the numerous small islands which lie off the coast of the Morbihan. In 1926 they were attracted by the evidence of a kitchen-midden exposed by marine erosion on this barren rock-it is little more, its dimensions being only four hundred metres in its greatest length and two hundred metres at its greatest breadth, while its elevation over the greater part of its extent is no more than ten metres-and began its excavation in July, 1928. After twenty-one days' excavation they were rewarded by the discovery of the first burial. The work of excavation was continued in 1929 and 1930 .

The island is completely barren, and even with the resources of modern civilization the excavating party found difficulty in keeping themselves provisioned 